\title{
Completing the global strategy: a missing element in preparation for pandemic influenza
}

\author{
Anthony Robbins ${ }^{1} \cdot$ Phyllis Freeman $^{2}$
}

Published online: 16 July 2018

(C) The Author(s) 2018

One hundred years ago, the 1918-1920 influenza pandemic began. Before it was over, it had killed 50-100 million people-more than the number who died in World War I. No influenza epidemic has ever again reached those proportions, but the threat of another massive pandemic is very real.

We are troubled because a fully open public health discussion does not appear to be taking place. In particular, how to respond to pandemic influenza before effective vaccines and antiviral treatments are available?

An overall strategy for pandemic influenza would logically include several distinct elements:

1. Public health Diminish transmission by limiting the contact that infected people have with people who lack immunity.

2. Vaccine Development Create and test vaccines to match the virus posing the pandemic threat.

3. Vaccination Vaccinate all at risk. (Or, if possible, rapidly vaccinate so as to encircle populations infected with the influenza virus, keeping them within a barrier of vaccinated people.)

4. Drug Development Create and test medications to treat influenza infections, such as antivirals and specific monoclonal antibodies. Then assure production and distribution for use worldwide.

5. AND prepare to save lives using every other credible approach.

\section{Anthony Robbins and Phyllis Freeman are Co-Editors of the Journal of Public Health Policy.}

Anthony Robbins

anthony.robbins@tufts.edu

1 Tufts University School of Medicine, Boston, MA, USA

2 University of Massachusetts, Boston, MA, USA 
We commend everyone who is working on the first four elements. Then we call on our public health and scientific colleagues to engage in an expansive and open discussion on element \#5-interventions to save lives early in a pandemic. Saving lives, after all, is the common goal for all elements of any public health strategy. Because it may not be wise or feasible to test all approaches at once, scientists and public health practitioners will have to choose top priorities. How will that be done so we can have confidence in their decision-making? Surely it must be possible to follow and understand the deliberations.

Even a rapid and successful effort to develop a safe and effective influenza vaccine will, at best, consume many months, starting when a strain becomes pandemic until when a vaccine to protect against it is being produced and widely distributed. During the first 6 months of an anticipated pandemic, estimates suggest that more than 30 million people could die. ${ }^{1}$ Is there a way early in the pandemic to reduce deaths among people exposed to the pandemic virus?

There is no proven strategy, but there are hints of strategies that might work. One such approach is described in the article that follows this Editorial. David Fedson describes how inexpensive and widely available drugs that modulate host responses to viral infections might reduce the death toll. ${ }^{2}$ It seems that many deaths from viral infections may be caused by the host's response.

We publish the Fedson article, not because it is certain that his proposal to test a combination of statins and angiotensin receptor blockers (ARBs) will be successful. Rather we ask why, when we looked at preparation and planning for pandemic influenza, we could find little or no mention of strategies that focused on modifying host response, (and, as Fedson suggests, using old drugs to do so).

We hope the cynical answer-that old drugs generate little profit for their makers-is wrong. The idea of targeting the host response to a pandemic influenza virus is more than 10 years old. Yet until now, scientists appear to have shown very little interest, and public health officials even less.

Finally, so-called 'repurposing' of already approved drugs, may be getting some attention if a recent announcement from the Broad Institute is an indication. The Institute (a joint effort of Harvard University and the Massachusetts Institute of Technology) is seeking "to acquire samples of every drug ever developed to see if they can be used to treat diseases besides those for which they were intended." 3 (We note, for example, that metformin, a drug commonly used to treat diabetes, is being examined for potential antiviral activity to treat dengue.)

At the peak of the Ebola epidemic in West Africa, a 2014 Op-Ed in The New York Times raised the question: Can statins help treat Ebola? The Ebola crisis in Sierra Leone might have offered a chance to conduct trials of drugs targeting the host response, but that opportunity has now passed by. Scientists and health officials

\footnotetext{
1 Fedson, D.S. Review: Treating influenza with statins and other immunomodulatory agents, Antiviral Research 99 (2013) 417-435.

2 Fedson, D.S. What Treating Ebola Means for Pandemic Influenza, JPHP 39-3.

3 Saltzman, J. This Cambridge nonprofit is seeking every drug ever developed. Boston Globe, 12 May 2018, accessed 16 May 2018 at: https://www.bostonglobe.com/business/2018/05/12/broad/CA4rG LXDReNvtLSrcgQhZL/story.html.
} 
(including those at WHO) rejected or failed to seize the opportunity. We don't know which or why.

Does the new Ebola outbreak in the Democratic Republic of Congo offer a chance to test drugs targeting the host response? Maybe, but it seems unlikely to happen. The situation is quite different today than during the 2014-2016 epidemic in Guinea, Liberia, and Sierra Leone. There are new interventions being tested in 2018 that were not available for the West African epidemic - a vaccine (known as rVSV-ZEBOV) and several experimental drugs, including ZMapp, a monoclonal antibody. And if efforts to contain transmission are successful, there will not be so many infected or ill. This is good news for fighting Ebola, but provides little solace for those concerned about the first several months of pandemic influenza.

Ways to save the lives of infected people deserve to be discussed as an element of a global influenza pandemic preparedness strategy. Treatment with inexpensive generic drugs might reduce influenza death tolls without preventing the viral disease. Or it might not. Without open discussion of all potential means to save lives, how can we know if decisions about priorities reflect serious and thorough consideration? Why aren't all reasonable questions discussed openly?

Open Access This article is distributed under the terms of the Creative Commons Attribution 4.0 International License (http://creativecommons.org/licenses/by/4.0/), which permits unrestricted use, distribution, and reproduction in any medium, provided you give appropriate credit to the original author(s) and the source, provide a link to the Creative Commons license, and indicate if changes were made. 